\title{
Preparation and electrochemical properties of $\mathrm{CPAC} / \mathrm{Mn}_{3} \mathrm{O}_{4}$ nanocomposite electrode
}

\author{
He-Ming Luo $\cdot$ Feng-Bo Zhang $\cdot$ Peng Yang
}

Received: 25 July 2012/Accepted: 8 November 2012/Published online: 20 November 2012

(C) The Author(s) 2012. This article is published with open access at Springerlink.com

\begin{abstract}
Novel nanocomposite electrode, coke powder activated carbon/ $\mathrm{Mn}_{3} \mathrm{O}_{4}\left(\mathrm{CPAC} / \mathrm{Mn}_{3} \mathrm{O}_{4}\right)$, was prepared by Sol-Gel method using CPAC/Mn $(\mathrm{OH})_{2}$ as a precursor. The $\mathrm{CPAC} / \mathrm{Mn}_{3} \mathrm{O}_{4}$ was characterized by field emission scanning electron microscopy and X-ray diffraction (XRD). The results show that the composite electrode material has a nano-rod structure and $\mathrm{Mn}_{3} \mathrm{O}_{4}$ is in mixed phase composed of $\mathrm{MnO}$ and $\mathrm{MnO}_{2}$. The influence factors on the electrochemical performance of electrode materials including manganese content of the precursor, different calcining temperature and time of the precursor were investigated. The results obtained from electrochemical measurement show that the electrode possesses better electrochemical performance with a manganese content of $20 \mathrm{wt} \%$ in precursor. In addition, the specific capacitance of $\mathrm{CPAC} / \mathrm{Mn}_{3} \mathrm{O}_{4}$ nanocomposite electrode material could reach up to $277 \mathrm{~F} \mathrm{~g}^{-1}$ at a calcining temperature of $500{ }^{\circ} \mathrm{C}$ and a calcining time of $3 \mathrm{~h}$, respectively.
\end{abstract}

\section{Introduction}

Supercapacitor has been considered as a new extremely valuable energy storage device, because of its excellent functions such as fast charging and discharging, high power, fairly high energy density, long cycle life, and friendly to environment [1-3]. Manganese oxide as supercapacitor

H.-M. Luo $(\bowtie)$ · F.-B. Zhang

School of Petrochemical Engineering, Lanzhou University

of Technology, Gansu 730050, China

e-mail: luohm666@163.com

P. Yang

Nanjing Shuangdeng Science and Technology Development

Academy Co., LTD, Jiangsu 225526, China electrode material is relatively inexpensive and innocuous to environment, which has great potentials as a kind of alternative electrode material in supercapacitor systems [4-8]. Manganese oxides present complex crystal structure of manganese oxides, for instance, the $\mathrm{MnO}_{2}$ includes types of $\alpha, \beta, \gamma, \delta, \varepsilon$ and $\rho$. The crystal structure of $\varepsilon, \rho, \gamma$ are similar to each other, $\delta$ belongs to the layer structure, and others belong to the chain structure. Owing to different crystal structure of manganese oxide, they often exhibit different electrochemical properties, among which $\gamma-\mathrm{MnO}_{2}$ shows a relatively high electrochemical active property $[9,10]$. So far, reports of manganese oxide used as electrode materials are mainly focused on $\gamma-\mathrm{MnO}_{2}$ and $\alpha-\mathrm{MnO}_{2}$ [11-14]. However, $\mathrm{Mn}_{3} \mathrm{O}_{4}$ used as electrode materials has rarely been reported.

Coke powder has been commonly known as the scrap material when the coke was produced in the process of the smashed in metallurgy, chemical industry, calcium carbide and other industries. Until now, the coke powder prepared by alkali activation has mainly been used in the wastewater treatment but seldom involved in electrode materials [15]. In this work, coke powder activated carbon and $\mathrm{CPAC} / \mathrm{Mn}_{3} \mathrm{O}_{4}$ composite electrode material were prepared in a continuation of our pervious study [16]. The electrochemical performance of $\mathrm{CPAC} / \mathrm{Mn}_{3} \mathrm{O}_{4}$ electrode materials, which was prepared under the conditions of different calcining temperature and time, were systematically investigated. Then the best preparation conditions were optimized.

\section{Experimental method}

\subsection{Preparation of $\mathrm{CPAC} / \mathrm{Mn}(\mathrm{OH})_{2}$}

Coke powder activated carbons (CPACs) were prepared according to previous study [16]. A certain quality of 
$\mathrm{MnCl}_{2} \cdot 4 \mathrm{H}_{2} \mathrm{O}$ was dissolved in $50 \mathrm{~mL}$ water, magnetic stirring with $30 \mathrm{~min}$, then according to 5,10,20,30,50 wt $\%$ of the amount of manganese added into CPAC, respectively, adding a few ethanol and stirring with $30 \mathrm{~min}$. After that $10 \mathrm{wt} \% \mathrm{NH}_{3} \cdot \mathrm{H}_{2} \mathrm{O}$ was added by $6-8$ drops per second,nearly for the $\mathrm{pH}=10$, and stirring with $6 \mathrm{~h}$. Then standly aging for $4 \mathrm{~h}$, depressurize filtering them, the products were fully rinsed to neutral and dried at $80{ }^{\circ} \mathrm{C}$ for $24 \mathrm{~h}$.

\subsection{Preparation of $\mathrm{CPAC} / \mathrm{Mn}_{3} \mathrm{O}_{4}$}

The prepared composite electrode materials was performed under the protection of $\mathrm{N}_{2}$, and calcined at different temperature $\left(300,400,500\right.$ and $\left.600{ }^{\circ} \mathrm{C}\right)$ for 2,3 , and $4 \mathrm{~h}$ respectively. After cooling down to room temperature, the sample was fully grinded in an agate mortar, and then put into the dryers.

\subsection{Preparation of $\mathrm{CPAC} / \mathrm{Mn}_{3} \mathrm{O}_{4}$ working electrodes}

The working electrodes were prepared for electrochemical measurement. CPAC/ $/ \mathrm{Mn}_{3} \mathrm{O}_{4}(80 \mathrm{wt} \%)$ was mixed with $10 \mathrm{wt} \%$ of acetylene black ( $>99.9 \%$ ) and $10 \mathrm{wt} \%$ of conducting graphite in an agate mortar and grinded equably. Then $5 \mathrm{wt} \%$ of polytetra-fluoroethylene (PTFE) aqueous suspension and a few drops of anhydrous ethanol were added into the $\mathrm{CPAC} / \mathrm{Mn}_{3} \mathrm{O}_{4}$ mixture. After removing the solvent by evaporation, the resulting paste was pressed into the nickel foam substrate using a spatula with a coating area of about $10 \mathrm{~mm} \times 10 \mathrm{~mm}$, and dried in vacuum at $80{ }^{\circ} \mathrm{C}$ for $2 \mathrm{~h}$, then the electrode of nickel foam was
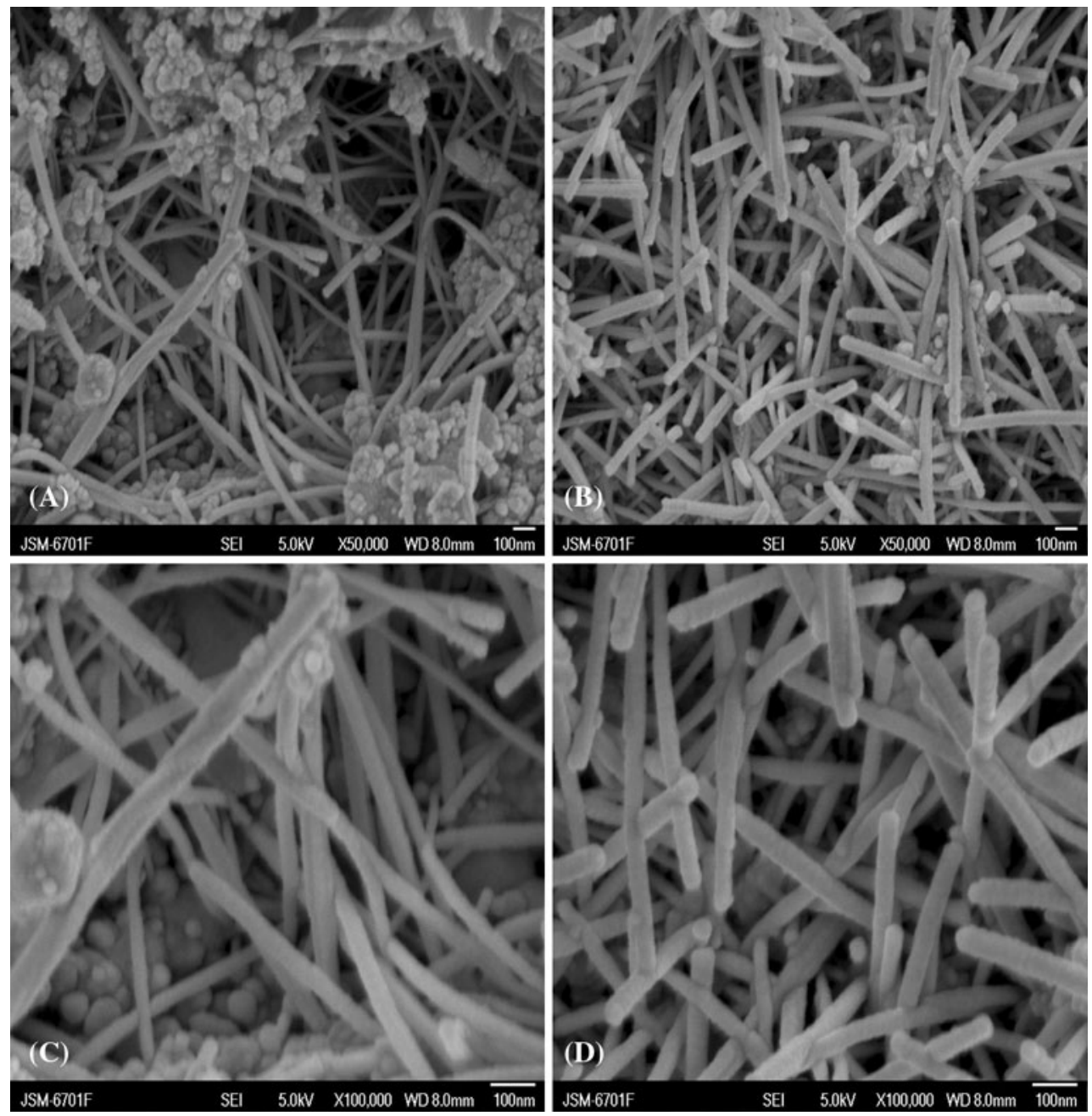

Fig. 1 The FESEM of the precursor $\mathrm{CPAC} / \mathrm{Mn}(\mathrm{OH})_{2}(\mathbf{a}$ and $\mathbf{c})$ and $\mathrm{CPAC} / \mathrm{Mn}_{3} \mathrm{O}_{4}$ composite material (b and d) 
pressed at $10 \mathrm{MPa}$ for $1-2 \mathrm{~min}$, and dried in vacuum for $4 \mathrm{~h}$.

\subsection{Characterization and electrochemical measurement}

The morphology of the electrodes was characterized by FESEM (JSM-6701F, Japan) and the structure was affirmed by XRD (RINT-2000, Japan). The electrochemical measurement of $\mathrm{CPAC} / \mathrm{Mn}_{3} \mathrm{O}_{4}$ electrodes was carried out using an electrochemical working station (CHI660B, Shanghai, China) in a three electrode cell at room temperature. A platinum gauze electrode and a saturated calomel electrode (SCE) served as the counter electrode and the reference electrode, respectively. $\mathrm{KOH}$ solution ( $2 \mathrm{~mol} \mathrm{~L}^{-1}$ ) was used as the electrolyte, each electrode possessed about $8 \mathrm{mg}$ of electro active material and had a geometric surface area of about $1 \mathrm{~cm}^{2}$. The charge and discharge properties of electrode materials, circulation current-voltage performance were measured.

\section{Results and discussion}

\subsection{FESEM analysis}

As shown in Fig. 1a, CPAC/Mn $(\mathrm{OH})_{2}$ prepared by SolGel method mainly shows a nano-wire shape, and some of which has granular structures. From Fig. 1c, we could clearly see the diameter of the nano-wire shaped precursor is in the range of $30-50 \mathrm{~nm}$. After calcining at $500{ }^{\circ} \mathrm{C}$ for $3 \mathrm{~h}$, the composite materials present a nanorod structure with a size of approximately $35 \mathrm{~nm}$ in diameter, as shown in Fig. 1b. Moreover, the number of granular $\mathrm{Mn}_{3} \mathrm{O}_{4}$ was significantly decreased. Based on Ostwald ripening process principle [17, 18], it is known that a large amount of manganese oxide was produced in the early calcinations. And these molecular gather to form crystal nucleus when they reach the critical state. With the extension of time, manganese and oxygen atoms are rearranged on the surface of manganese oxide [19]. Then the small particles also attach to the surface of crystal nucleus, which makes directional growth of the manganese oxide, and gradually grow into nano-rods [20]. Nano-rods composite material of CPAC/ $/ \mathrm{Mn}_{3} \mathrm{O}_{4}$ was prevalently easy to be touched or attached by the active substances and the ions in electrolyte, which facilitate to the $\mathrm{H}+$ or $\mathrm{OH}-$ removing from the pore channel of nanocomposite material, produced by reaction and prompted to evacuate. Therefore, the active substance $\left(\mathrm{Mn}_{3} \mathrm{O}_{4}\right)$ in the nanocomposite material could be fully utilized.

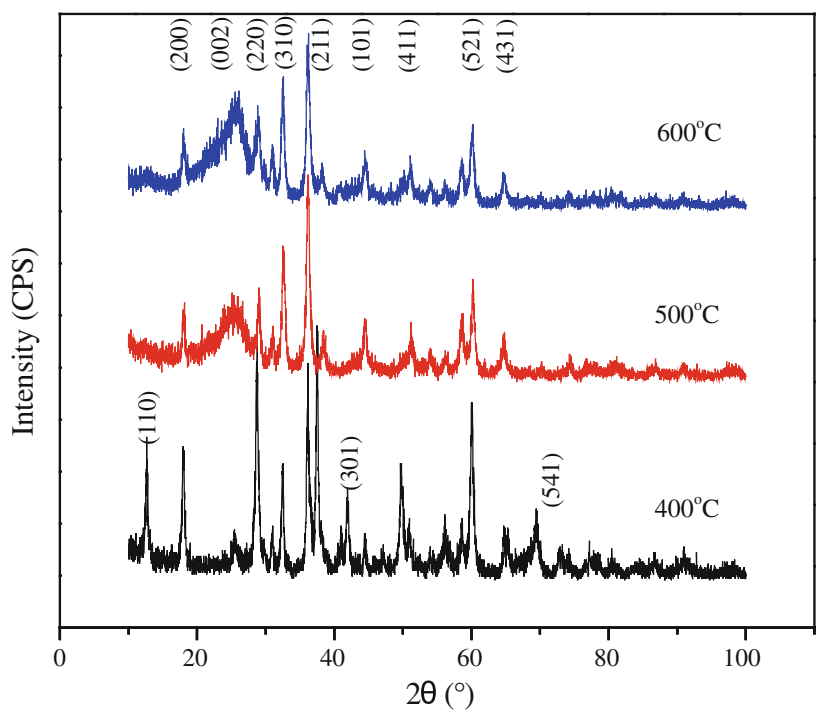

Fig. 2 The XRD patterns of nanocomposite materials at different calcined temperatures

\section{$3.2 \mathrm{XRD}$}

The XRD patterns of nanocomposite materials at different calcining temperatures are shown in Fig. 2. For preparation of nanocomposite materials at a calcining temperature of $400{ }^{\circ} \mathrm{C}$, diffraction planes appeared on (110), (200), (220), (210), (521) and (541), corresponding to the characteristics of $\alpha-\mathrm{MnO}_{2}$ [21]. While calcining at $500{ }^{\circ} \mathrm{C}$ and $600{ }^{\circ} \mathrm{C}$, diffraction planes appeared on (200), (220), (310), (411), (521) and (431) could be indexed to the structure of $\mathrm{Mn}_{3} \mathrm{O}_{4}$ (JCPDS 24-0734). These results indicate that the lower calcining temperature facilitates the precursors of nanocomposite materials to change into $\alpha-\mathrm{MnO}_{2}$. At higher temperature, it makes manganese oxide more likely to be the mixed phase of $\mathrm{Mn}_{3} \mathrm{O}_{4}$. In addition, when the temperature was higher than $500{ }^{\circ} \mathrm{C}$ (e.g. $600{ }^{\circ} \mathrm{C}$ ), the diffraction peak of $\mathrm{Mn}_{3} \mathrm{O}_{4}$ obviously decreased. Therefore, in this work, the preparation conditions for of nanocomposite materials were optimized as calcining of precursor at $500{ }^{\circ} \mathrm{C}$ for $3 \mathrm{~h}$.

\subsection{Charge/discharge test of CPAC/Mn $(\mathrm{OH})_{2}$}

The specific capacitance was evaluated from the charge/ discharge test combination with the following equation:

$$
\begin{aligned}
C & =I /[(\mathrm{d} E / \mathrm{d} t) \times m] \approx I /[(\Delta E / \Delta t) \times m] \\
& =\frac{I \times \Delta t}{\Delta E \times m}\left(\mathrm{~F} \mathrm{~g}^{-1}\right)
\end{aligned}
$$

In the above equation, $C$ is the specific capacitance; $I$ is the constant discharging current; $\Delta t$ is the time period for 


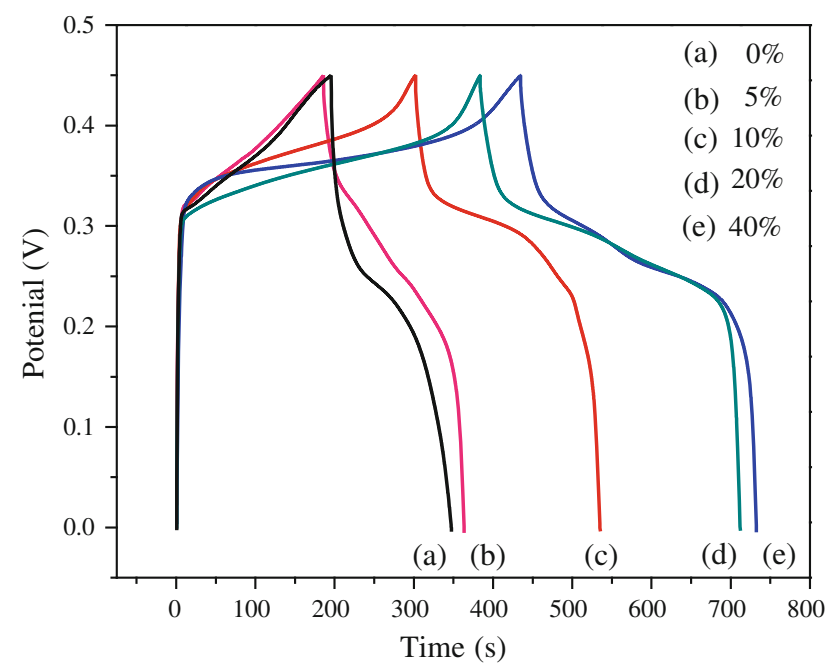

Fig. 3 The constant current charge/discharge curves of precursors prepared in the different manganese contents

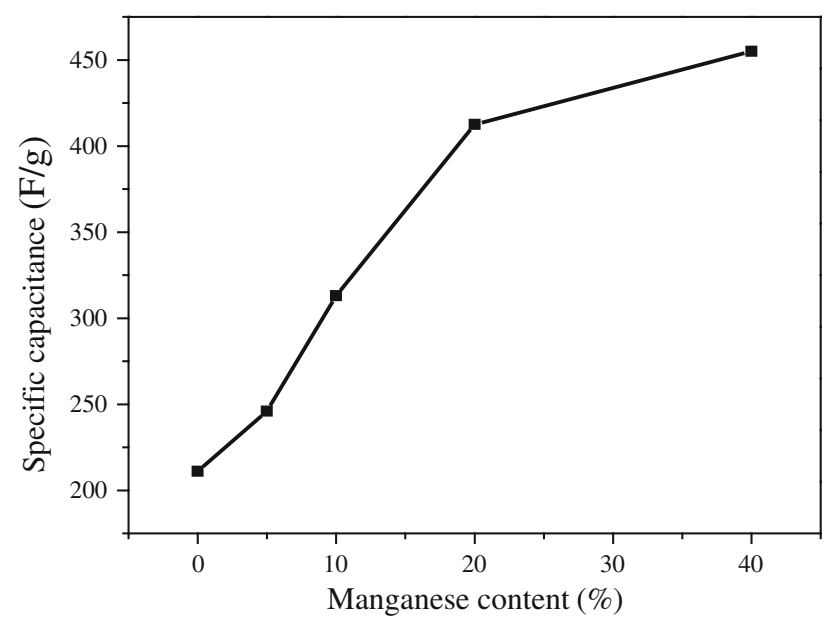

Fig. 4 The specific capacitance of precursors prepared in the different manganese contents

the potential change $\Delta E$; and $m$ is the mass of the electrode materials measured.

The constant current charge/discharge curves of precursors prepared with different manganese contents are shown in Fig. 3. The test conditions were set as follows: current density $=5 \mathrm{~mA} / \mathrm{cm}^{2}$, voltage windows over $0-0.45 \mathrm{~V}$. It is clearly that the precursor's constant current charge/discharge time extends gradually with the increase of mass proportion of manganese contents when manganese compound is less than $20 \mathrm{wt} \%$. It indicates that the manganese compound has a positive impact on the electrochemical performance of CPAC electrode materials. When the manganese content is more than $20 \mathrm{wt} \%$, specific capacitance of $\mathrm{CPAC} / \mathrm{Mn}(\mathrm{OH})_{2}$ begins to increase slowly. The specific capacitance reaches up to $455 \mathrm{~F}$ g-1 with a manganese content of $40 \mathrm{wt} \%$. This phenomenon can be explained by the following reasons: when the content of manganese in composite surpasses $20 \mathrm{wt} \%$, Faraday active substances $\mathrm{Mn}(\mathrm{OH})_{2}$ increases gradually and substantial accumulation and granular reunion emerges in the inner surface of CPAC samples. However, it is difficult for the electrolyte ions to access the pore structure of CPAC samples, and it is hardly to contact between the active substances and electrolyte ions each other. Therefore, the Faraday pseudo-capacitance effect of the active material is reduced. Moreover, the decrease in the electric double layer effect of CPAC samples also leads to a lower specific capacitance.

The specific capacitances of precursors prepared with the different manganese contents are presented in Fig. 4. With the manganese contents in precursors of $5,10,20$, $40 \mathrm{wt} \%$, the specific capacitances of precursor were measured to be 246, 323, 412.5 and $455 \mathrm{~F} \mathrm{~g}^{-1}$, respectively. Compared with that of the CPAC sample $\left(211 \mathrm{~F} \mathrm{~g}^{-1}\right)$ [16], the capacitances increased by 16.6, 53.1, 95.9 and $115.6 \%$ respectively. This results show that specific capacitance of $\mathrm{CPAC} / \mathrm{Mn}(\mathrm{OH})_{2}$ precursor has a positive relationship with the content of manganese less than $20 \mathrm{wt} \%$. When the content of manganese is more than $20 \mathrm{wt} \%$, the increase rate of specific capacitance becomes slowly. Consequently, $20 \mathrm{wt} \%$ of manganese content in the composite electrode material precursor of $\mathrm{CPAC} / \mathrm{Mn}(\mathrm{OH})_{2}$ should be an optimum value.

\subsection{The electrochemical characterizations of CPAC/ $\mathrm{Mn}_{3} \mathrm{O}_{4}$}

\subsubsection{Chronopotentiometry}

The influence on the specific capacitance of composite electrode materials at different calcining temperature and time were investigated and the results are shown in Fig. 5. It can be seen from Fig. 5, when the calcining temperature is less than $500{ }^{\circ} \mathrm{C}$, for the same calcining time, the specific capacitance of composite electrode material sharply declines with the increase of temperature, but for the entire range it shows an increasing trend. When the temperature is higher than $500{ }^{\circ} \mathrm{C}$ and the calcining time is more than $2 \mathrm{~h}$, the specific capacitance of composite material reduces on the contrary (such as calcining temperature of $600{ }^{\circ} \mathrm{C}$, calcining time for $3 \mathrm{~h}$ and $4 \mathrm{~h}$ ). Firstly, at the same calcining temperature, the composite materials' specific capacitance sharply reduces than precursor, and then they had an increasing tendency with prolonging the calcining time. As the calcining time prolongs over $3 \mathrm{~h}$, the composite material exhibits a lower specific capacitance. Owing to the increase of calcining temperature and the gradually extension of calcining time, $\mathrm{Mn}(\mathrm{OH})_{2}$ in the precursor starts to dehydrate and transform to manganese 


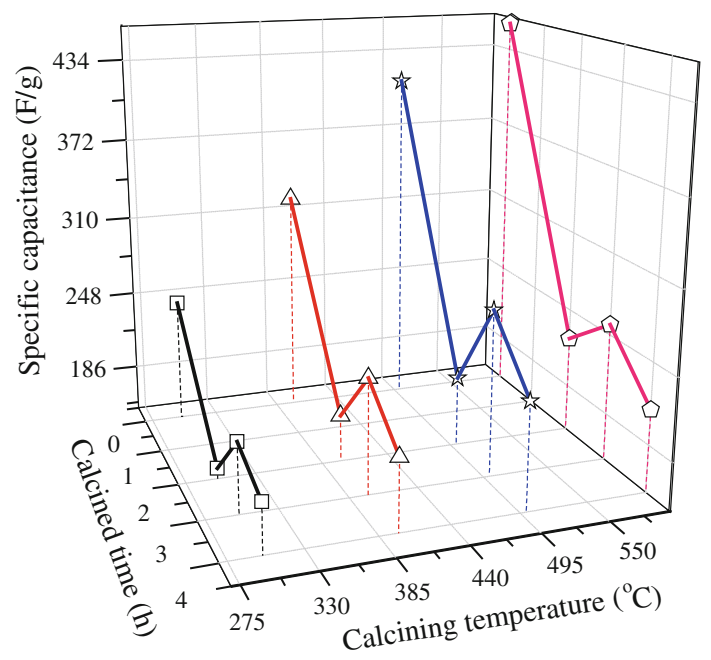

Fig. 5 The influence on the specific capacitance of nanocomposite electrodes at different calcining temperatures and time

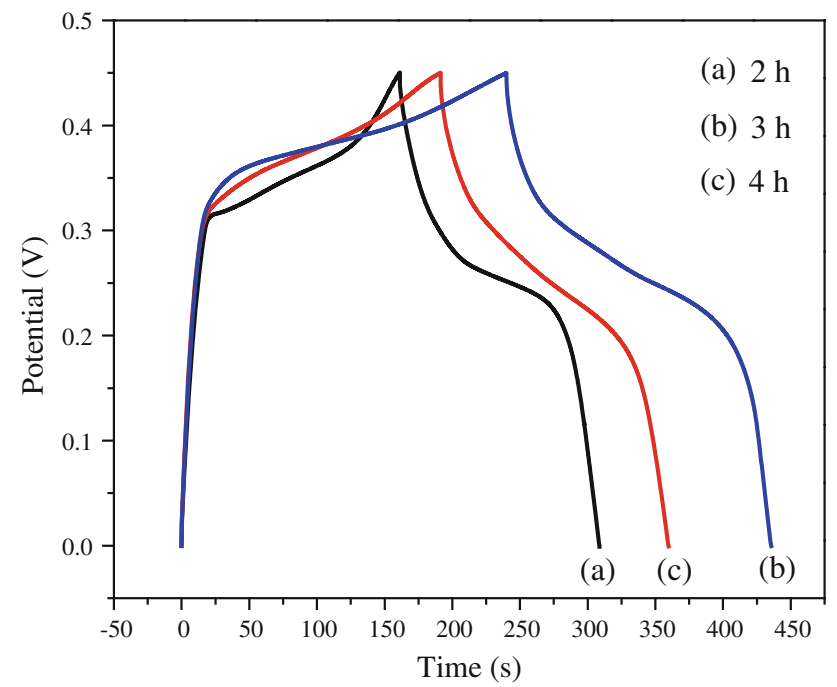

Fig. 6 The constant current charge/discharge curves of composite materials prepared in the calcining temperature is $500{ }^{\circ} \mathrm{C}$ and the different calcining time

oxide with higher stability. Manganese oxide could hardly react with the electrolyte, the mass transfer in manganese oxide ions is then more difficult than that of in $\mathrm{Mn}(\mathrm{OH})_{2}$, resulting in the decrease of specific capacitance of CAPC/ $\mathrm{Mn}_{3} \mathrm{O}_{4}$. With the extension of calcining time, the precursor could completely transform into manganese oxide, which in turn causes its crystal growth. With the large amount of manganese oxide appeared, the Faraday Effect enhanced as well, which would cause the increase of the specific capacitance. In the same way, because the raising of temperature is beneficial to the crystal growth of manganese oxide, composite electrode material exhibits an increased specific capacitance with the increase of calcining temperature. However, the composite electrode materials

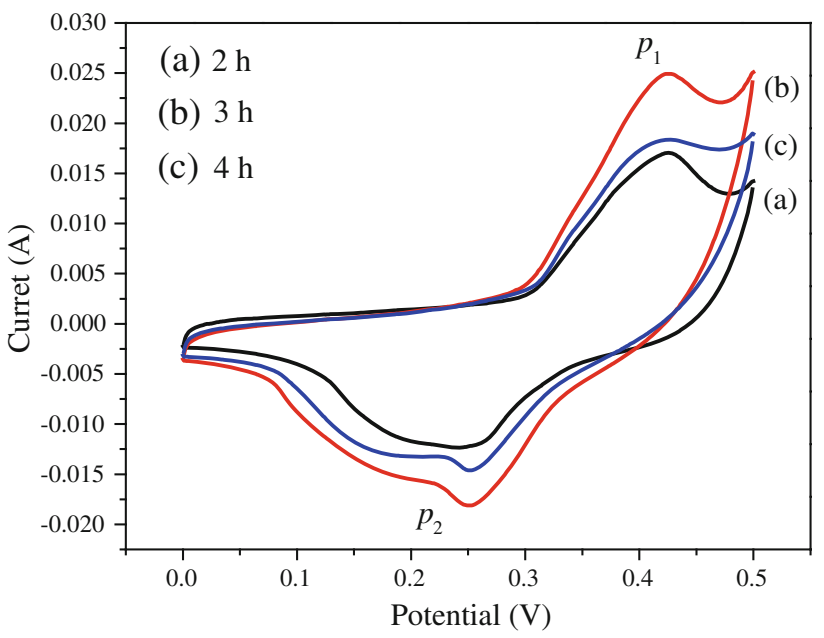

Fig. 7 The cyclic voltammograms of composite materials prepared in the calcined temperature is $500{ }^{\circ} \mathrm{C}$ and the different calcined time

possess a lower specific capacitance when the calcining time exceeds $3 \mathrm{~h}$, which may be due to the change of crystal structure of manganese oxide for a longer calcining time. This phenomenon is unfavorable to the formation of $\mathrm{Mn}_{3} \mathrm{O}_{4}$. As a result, the composite electrode materials of $\mathrm{CPAC} / \mathrm{Mn}_{3} \mathrm{O}_{4}$ exhibits better specific capacitance at a calcining temperature of $500{ }^{\circ} \mathrm{C}$.

The constant current charge/discharge curves of CPAC/ $\mathrm{Mn}_{3} \mathrm{O}_{4}$ are shown in Fig. 6. The specific capacitance of composite electrode materials prepared at a calcining time for 2,3 and $4 \mathrm{~h}$ (calcining temperature is $500{ }^{\circ} \mathrm{C}$ ) were calculated to be 204,277 and $232 \mathrm{~F} \mathrm{~g}^{-1}$, respectively. We found that the specific capacitance of nanocomposite electrode materials is lower than that of the CPAC samples itself $\left(211 \mathrm{~F} \mathrm{~g}^{-1}\right)$ with a calcining time of $2 \mathrm{~h}$. In addition, the $\mathrm{Mn}(\mathrm{OH})_{2}$ on the inner surface of nanocomposite electrode material tends to transform into manganese oxide after calcining, which would lead to a decrease in the specific surface area of nanocomposite electrode and reduction of the composite electric double layer effect. With a calcining time of $3 \mathrm{~h}$, the specific capacitance of nanocomposite electrode material was measured to be $277 \mathrm{~F} \mathrm{~g}^{-1}$, which is higher than that of $266 \mathrm{~F} \mathrm{~g}-1$ under the scanning rate of $1 \mathrm{mV} / \mathrm{s}$ as Ref. reported [22].

\subsubsection{Cyclic voltammetry}

From Fig. 7, we could obtain that the oxidation and reduction peak potential value of nanocomposite materials increased with the increase of the calcination temperature, and decreased with further prolonging the calcination temperature. The results indicate that the energy storage performance composite electrode material firstly enhanced with the increasing calcining temperature then decreased as 


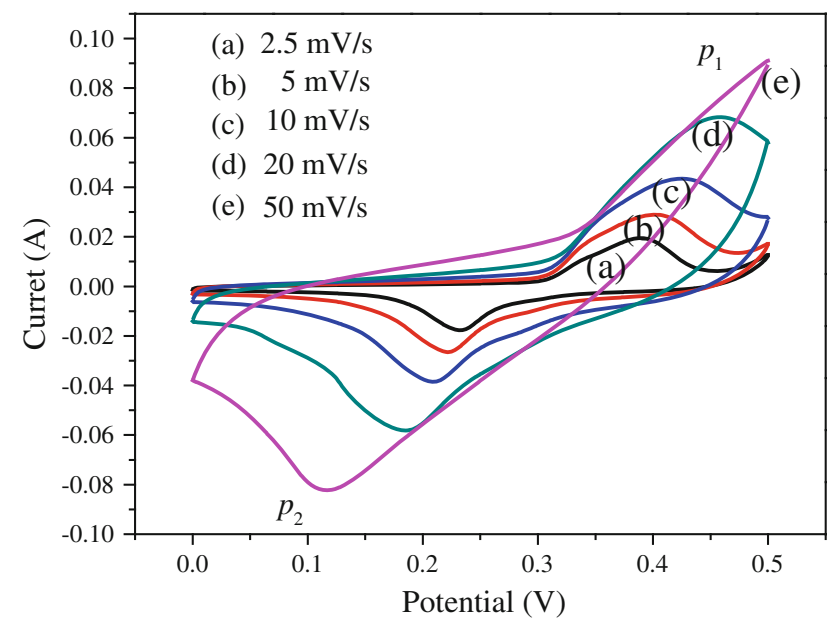

Fig. 8 The cyclic voltammograms of composite materials prepared in the calcined temperature is $500{ }^{\circ} \mathrm{Cand}$ the calcined time is $3 \mathrm{~h}$ at various scan rates

well, which is consistent with the constant current charging/discharging test.

As shown in Fig. 8, with the increase of the scanning rate, anode peak potential of REDOX positively moved, and the cathode peak potential moved negatively, which leads to a larger difference between two peak potential values of REDOX. Under lower scanning rate, the difference of peak potential value is smaller. When the scanning rate was set as $50 \mathrm{mV} / \mathrm{s}$, no complete REDOX peaks was observed in the same voltage window. Owing to the increase of the scanning rate, the polarization effect on nanocomposite electrode materials enhanced. The degree of irreversible reaction is strengthened, which results in the reduction of specific capacitance.

\section{Conclusions}

Employing CPAC as a matrix, the precursor CPAC/ $\mathrm{Mn}(\mathrm{OH})_{2}$ were prepared by Sol-Gel method. The CPAC/ $\mathrm{Mn}_{3} \mathrm{O}_{4}$ nanocomposite electrode materials were then obtained by calcination of the precursor. FESEM images show that the manganese oxide embedded in the nanocomposite electrode has a nano-rod structure. Electrochemical test results show that the precursor has a relatively good electrochemical performance when the manganese content is $20 \mathrm{wt} \%$. With $20 \mathrm{wt} \%$ manganese content in precursor, under a calcining temperature of $500{ }^{\circ} \mathrm{C}$ and a calcining time of $3 \mathrm{~h}$, the nanocomposite electrode material exhibits a better electrochemical performance and its specific capacitance reaches up to $277 \mathrm{~F} \mathrm{~g}^{-1}$.

Acknowledgments This work was financially supported by the Funds for Creative Research Groups of China (Grant NO.51121062) and Excellent Young Teachers in Lanzhou University of Technology Training Project (Grant NO.1005ZCX016).

Open Access This article is distributed under the terms of the Creative Commons Attribution License which permits any use, distribution, and reproduction in any medium, provided the original author(s) and the source are credited.

\section{References}

1. K. Okajima, K. Ohta, M. Sudoh, Electrochim. Acta 50, 2227 (2005)

2. C. Portet, P.L. Taberna, P. Simon, Electrochim. Acta 50, 4174 (2005)

3. A. Burke, J. Power Sources 91, 37 (2000)

4. Z. Sun, K.Y. Liu, H.F. Zhang et al., Acta Phys. Chim. Sin. 25, 1991 (2009)

5. L.C. Li, K. Lafdi, J. Mater. Sci. 46, 7328 (2011)

6. S.C. Yan, J.S. Wu, J. Nanjing Univ. Posts Telecommun. (Nat. Sci.). 31, 134 (2011)

7. S.J. Li, S.L. Wang, B. Xu, Chin. J. Chem. Eng. 59, 514 (2008)

8. E.H. Liu, R. Ding, X.Y. Meng, S.T. Tan, J.C. Zhou, J. Mater. Sci. Mater. Electron. 18, 1179 (2007)

9. L.I. Hill, A. Verbaere, D. Guyomard, J. Power Sources 119/121, 226 (2003)

10. Z.D. Chen, L. Gao, J.Y. Cao, Acta Chim. Sinica 69, 503 (2011)

11. J. Yan, Z.J. Fan, T. Wei, M.L. Zhang, J. Mater. Sci. Mater. Electron. 21, 619 (2010)

12. L.F. Wan, X.P. Huang, F. Mao, J. China Three Gorges Univ. (Nat. Sci.). 30, 108 (2008)

13. X.Y. Wang, X.Y. Wang, T.L. Hou, Chin. J. Chem. Eng. 57, 442 (2006)

14. X.Y. Wang, X.Y. Wang, W.G. Huang, J. Power Sources 140, 211 (2005)

15. H.M. Luo, S.R. Yu, H.X. Feng, J. China Coal Soc. 34, 971 (2009)

16. H.M. Luo, P. Yang, F.B. Zhang, J. Mater. Sci. Mater. Electron. Online first. doi:10.1007/s10854-012-0838-y (2012)

17. N. Tang, X.K. Tian, C. Yang, Mater. Res. Bull. 71, 258 (2010)

18. H. Gui, H.C. Zeng, J. Phys Chem B. 8, 3492 (2004)

19. N. Kijima, H. Yasuda, T. Sato, J. Solid State Chem. 159, 94 (2001)

20. Y.C. Gui, L.W. Qian, X.F. Qian, Chinese. J. Inorg. Chem. 25, 668 (2009)

21. S.Y. Qi, J. Feng, J. Yan, Chin. J. Nonfer. Metal. 18, 113 (2008)

22. T.X. Zhou, S.S. Mo, S.L. Zhou, J. Mater. Sci. 46, 3337 (2011) 